\title{
A Gold(I) Oxide Double Perovskite: $\mathrm{Ba}_{2} \mathrm{AuIO}_{6}$
}

Elizabeth A. Pogue,,$+\neq$ Jack Bond, Cassandra Imperato,,$\$$, John B.S. Abraham," Natalia Drichko, $\stackrel{\ddagger}{\ddagger}$ and Tyrel M. McQueen $*,+,, \xi, \uparrow$

$\dagger$ Department of Chemistry, The Johns Hopkins University, Baltimore, MD, 21218, USA

$\ddagger$ Institute for Quantum Matter, The Johns Hopkins University, Baltimore, MD, 21218, USA

IDepartment of Materials Science and Engineering, The Johns Hopkins University, Baltimore, MD, 21218, USA

$\S$ Department of Physics and Astronomy, The Johns Hopkins University, Baltimore, MD, 21218, USA

|| Johns Hopkins University Applied Physics Laboratory, Laurel, MD, 20723, USA

E-mail: mcqueen@jhu.edu

\section{Supporting Information Available}

Detailed synthesis procedures of $\mathrm{Ba}_{2} \mathrm{NaIO}_{6}, \mathrm{Ba}_{2} \mathrm{AgIO}_{6}$, and $\mathrm{Ba}_{2} \mathrm{AuIO}_{6}$ with details also of our failed attempts at making $\mathrm{Ba}_{2} \mathrm{BiIO}_{6}$, refined NOMAD neutron PDF data, $\mathrm{Ba}_{2} \mathrm{NaIO}_{6}$ refinement information, bond lengths, heat capacity information, FTIR data for all compounds, CIF files for all synthesized phases. The code used to modify Z2Pack is made available on Github: https://github.com/euclidmenot2/Z2Pack. 


\section{Synthesis}

Our hydrothermal synthesis route was adapted from Sleight et al. to reduce its sensitivity to $\mathrm{CO}_{2} \cdot{ }^{1}$ The original technique was highly sensitive to $\mathrm{CO}_{2}$ from the atmosphere so our procedure was carried out under Ar using air-free schlenck techniques using degassed deionized (DI) water. Deionized (DI) water was degassed for at least $1 \mathrm{~h}$ by bubbling Ar through it.

$\mathrm{Au}_{2} \mathrm{O}_{3}$ (Alfa Aesar Premion $99.99 \%$ (metals basis)) was the $\mathrm{Au}$ source for $\mathrm{Ba}_{2} \mathrm{AuIO}_{6}$. To provide $\mathrm{Ag}$ for $\mathrm{Ba}_{2} \mathrm{AgIO}_{6}, \mathrm{AgNO}_{3}$ (Alfa Aesar ACS grade $99.9+\%$ (metals basis)) and $\mathrm{NaOH}$ (pellets, VWR ACS reagent grade) were reacted with a $\mathrm{NaOH}$ excess to form $\mathrm{Ag}_{2} \mathrm{O}$. The $\mathrm{Ag}_{2} \mathrm{O}$ intermediate in the $\mathrm{Ba}_{2} \mathrm{AgIO}_{6}$ reaction was filtered and washed with degassed DI water several times under $\mathrm{Ar}$ to minimize the formation of $\mathrm{Ag}_{2} \mathrm{CO}_{3}$. We verified that $\mathrm{Ag}_{2} \mathrm{O}$ formed during an early synthesis but did not check each batch to reduce the likelihood of introducing $\mathrm{CO}_{2}$. These were placed in a flask.

$\mathrm{Ba}(\mathrm{OH})_{2} \cdot 8 \mathrm{H}_{2} \mathrm{O}$ (Acros Organics $99.95 \%$ ) was dissolved in degassed DI water in a separate flask. This solution was filtered to remove $\mathrm{BaCO}_{3}$ impurity and transferred to the flask containing $\mathrm{Au}_{2} \mathrm{O}_{3}$ or $\mathrm{Ag}_{2} \mathrm{O} . \mathrm{H}_{5} \mathrm{IO}_{6}$ powder (99+\% Acros Organics) was dissolved in degassed DI water and transferred to the $\mathrm{Au}_{2} \mathrm{O}_{3} / \mathrm{Ag}_{2} \mathrm{O}$ and $\mathrm{Ba}(\mathrm{OH})_{2}$ solution. The molar ratio of $\left.\mathrm{Ba}(\mathrm{OH})_{2}\right) \cdot 8 \mathrm{H}_{2} \mathrm{O}$ to $\mathrm{H}_{5} \mathrm{IO}_{6}$ was $2: 1$ while the molar ratio of $\mathrm{Ag}_{2} \mathrm{O}$ or $\mathrm{Au}_{2} \mathrm{O}_{3}$ to $\mathrm{Ba}(\mathrm{OH})_{2} \cdot 8 \mathrm{H}_{2} \mathrm{O}$ was 1:1.2. Consequently, the amount of transition metal limited the reaction. For various syntheses, we aimed for between $300 \mathrm{mg}$ and $800 \mathrm{mg}$ of final $\mathrm{Ba}_{2} \mathrm{AgIO}_{6}$ and $300 \mathrm{mg}$ of $\mathrm{Ba}_{2} \mathrm{AuIO}_{6}$.

These solutions were heated to $95-100^{\circ} \mathrm{C}$ in a boiling water bath. Over a 1 to $2 \mathrm{~h}$ period in the $\mathrm{Ba}_{2} \mathrm{AuIO}_{6}$ synthesis, the precipitate first gained some pale pinkish streaks before turning a darker orange-brown. For the $\mathrm{Ba}_{2} \mathrm{AgIO}_{6}$ synthesis, a blue-gray precipitate formed immediately after $\mathrm{H}_{5} \mathrm{IO}_{6}$ addition with a few darker specks. These specks disappeared relatively quickly $(15 \mathrm{~min})$ and seemed distinct from the bulk of the material. There were no notable yellow grains observed that would suggest that $\mathrm{AgI}$ or $\mathrm{AgIO}_{4} \cdot \mathrm{H}_{2} \mathrm{O}$ formed. ${ }^{[2]}$ Over a $\sim 1 \mathrm{~h}$ period, the precipitate turned first coffee-colored then deep brown. After at least $6 \mathrm{~h}$, 
the solutions were allowed to cool.

To prevent the introduction of $\mathrm{BaCO}_{3}$ from unreacted $\mathrm{Ba}(\mathrm{OH})_{2}$, it was necessary to either filter and rinse with degassed DI water under Ar or filter and rinse extremely quickly using a very large Buchner funnel such that the solution did not have time to pool. If the samples were rinsed using ethanol without the initial water rinses, large amounts of $\mathrm{BaCO}_{3}$ would form. Once clean, the $\mathrm{Ba}_{2} \mathrm{AuIO}_{6}$ and $\mathrm{Ba}_{2} \mathrm{AgIO}_{6}$ were significantly more stable in air, with changes noticeable (development of $\mathrm{BaCO}_{3}$ impurity phase visible in XRD) only after several months.

We also attempted to make $\mathrm{Ba}_{2} \mathrm{AgIO}_{6}$ at $350{ }^{\circ} \mathrm{C}$ over $10 \mathrm{~h}$ using $\mathrm{AgIO}_{4}$ and $\mathrm{Ba}(\mathrm{OH})_{2}$ in air. Although poorly crystalline $\mathrm{Ba}_{2} \mathrm{AgIO}_{6}$ represented a major phase in the resulting dry powder, comparable amounts of $\mathrm{BaCO}_{3}$ and $\mathrm{AgI}$ formed as well. $350{ }^{\circ} \mathrm{C}$ was chosen to avoid decomposition of $\mathrm{AgIO}_{3}$ at $405^{\circ} \mathrm{C} \cdot \frac{3}{3}$ Near $200^{\circ} \mathrm{C}, \mathrm{AgIO}_{4}$ decomposes into $\mathrm{AgI}$ and $\mathrm{AgIO}_{3}$, partially explaining the presence of $\mathrm{AgI}$. Since the $\mathrm{Ba}_{2} \mathrm{AgIO}_{6}$ crystallinity was not improved by this higher-temperature synthesis, no further investigations of solid-state routes to $\mathrm{Ba}_{2} \mathrm{AgIO}_{6}$ were performed.

Attempts at synthesizing $\mathrm{Ba}_{2} \mathrm{BiIO}_{6}$ using $\mathrm{Bi}_{2} \mathrm{O}_{3}$ precursor following the hydrothermal technique described above were unsuccessful. Similarly, attempts at synthesizing $\mathrm{Ba}_{2} \mathrm{BiIO}_{6}$ using $\mathrm{BiIO}_{4}$ following the solid-state procedure used for $\mathrm{Ba}_{2} \mathrm{NaIO}_{6}$ were similarly unsuccessful and resulted in various mixtures of $\mathrm{BiIO}_{4}$, barium oxides, and $\mathrm{Bi}_{2} \mathrm{O}_{3}$.

When using $\mathrm{Bi}_{2}\left(\mathrm{NO}_{3}\right)_{3} \cdot 5 \mathrm{H}_{2} \mathrm{O}, \mathrm{HIO}_{3}$, and $\mathrm{Ba}(\mathrm{OH})_{2} \cdot 8 \mathrm{H}_{2} \mathrm{O}$ or $\mathrm{Bi}_{2}\left(\mathrm{NO}_{3}\right)_{3} \cdot 5 \mathrm{H}_{2} \mathrm{O}, \mathrm{HIO}_{3}$, and $\mathrm{Ba}\left(\mathrm{NO}_{3}\right)_{2}$ for hydrothermal reactions at $180^{\circ} \mathrm{C}$ over $24 \mathrm{~h}$, we obtained mostly $\mathrm{BiIO}_{4}$ with some $\mathrm{Bi}_{2} \mathrm{O}_{2} \mathrm{OHNO}_{3}$ in the first case. Similarly, a white powder containing mostly $\mathrm{Bi}_{2} \mathrm{O}_{3}$ was the product when $\mathrm{Bi}_{2} \mathrm{O}_{3}$ was substituted directly for $\mathrm{Au}_{2} \mathrm{O}_{3}$ in the reaction successfully used for $\mathrm{Ba}_{2} \mathrm{AuIO}_{6}$.

Solid-state techniques were also attempted. Annealing of $\mathrm{BiIO}_{4}$ with $\mathrm{Ba}(\mathrm{OH})_{2} \cdot 8 \mathrm{H}_{2} \mathrm{O}$ does not yield $\mathrm{Ba}_{2} \mathrm{BiIO}_{6}$ either. Instead, it yields primarily $\mathrm{BiIO}_{4}$ and $\mathrm{BaO}$ at $325^{\circ} \mathrm{C}(20 \mathrm{~h})$ and primarily $\mathrm{Bi}_{2} \mathrm{O}_{3}$ at $650{ }^{\circ} \mathrm{C}(20 \mathrm{~h})$. In addition, attempts to synthesize $\mathrm{Ba}_{2} \mathrm{BiIO}_{6}$ using $\mathrm{BiOI}$ 
and $\mathrm{BaO}_{2}$ at $300{ }^{\circ} \mathrm{C}$ and $400{ }^{\circ} \mathrm{C}$ were similarly unsuccessful, with no change in the precursors at $300{ }^{\circ} \mathrm{C}$ and decomposition of the $\mathrm{BiOI}$ at $400{ }^{\circ} \mathrm{C}$ (observed a mix of $\mathrm{BaO}_{2}$ and $\mathrm{Bi}_{5} \mathrm{IO}_{7}$ ).

If the $\mathrm{Ba}_{2} \mathrm{AgIO}_{6}$ or $\mathrm{Ba}_{2} \mathrm{AuIO}_{6}$ powders were placed in neutral to slighly acidic deionized water after drying, they begin to decompose. The washed powders were more stable when suspended in ethanol. Ethanol was used to mount the laboratory XRD samples since both compounds decompose when exposed to vaseline.

\section{FTIR}




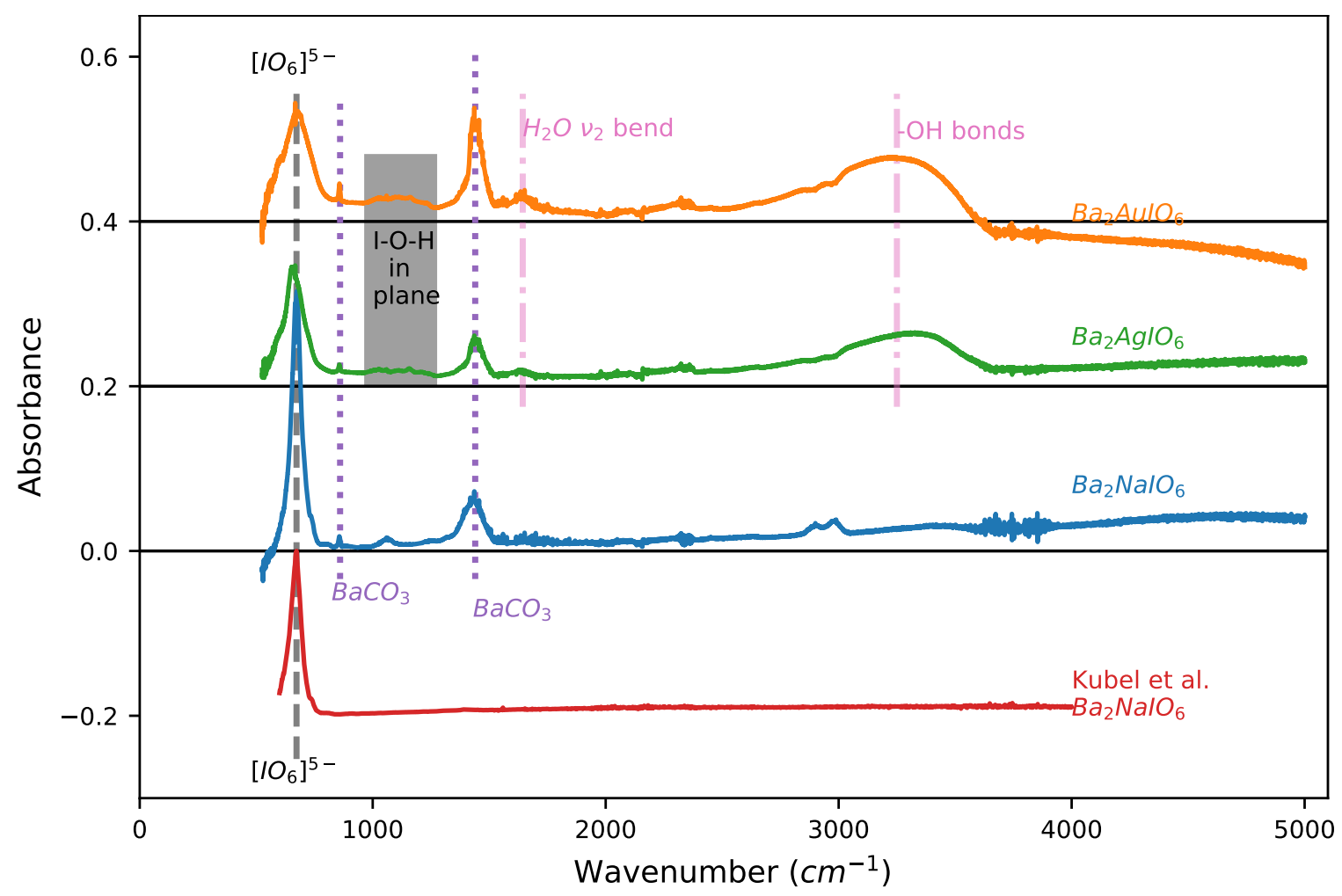

Figure S1: FTIR data shows clear $\mathrm{O}-\mathrm{H}$ bonds in the $\mathrm{Ba}_{2} \mathrm{AgIO}_{6}$ and $\mathrm{Ba}_{2} \mathrm{AuIO}_{6}$ samples. Attribution of periodate peaks was done based on the analysis of Hans Siebert and Gertraud Wieghardt of $\mathrm{H}_{5} \mathrm{IO}_{6}, \mathrm{H}_{6} \mathrm{IO}_{6}{ }^{+}$, and $\mathrm{IO}_{6}{ }^{5-}$. 4 Small peaks between 970 and 1280 observable primarily in the $\mathrm{Ba}_{2} \mathrm{AgIO}_{6}$ and $\mathrm{Ba}_{2} \mathrm{AuIO}_{6}$ spectra were attributed to I-O-H in-plane vibrations. Water and $\mathrm{BaCO}_{3}$ attributions were made based on the NIST database. ${ }^{[16}$ The peak near $1450 \mathrm{~cm}^{-1}$ was not visible in Kubel's $\mathrm{Ba}_{2} \mathrm{NaIO}_{6}$, which did not have any observed $\mathrm{BaCO}_{3}$ impurity. Since the strongest $\mathrm{BaCO}_{3}$ absorbance is located at this wavenumber and $\mathrm{BaCO}_{3}$ was present in all samples, this peak was attributed to $\mathrm{BaCO}_{3} \cdot{ }^{7}$ There was no evidence of H-I bonding. If such bonding were present, one would expect to see a H-I stretch near $2463 \mathrm{~cm}^{-1}$. 


\section{1-BM and NOMAD Refinements}

The 11-BM samples were diluted with a suitable amount of quartz to reduce x-ray absorption to a suitable level. Measurements were performed with $\lambda=0.457856 \AA$ for $2 \theta=0.5-50^{\circ}$ in 43053 steps separated by $0.0009984375^{\circ}$ with a dwell time of $\left.0.1 \mathrm{~s} / \mathrm{step}, \mathrm{SI}\right)$.

For consistency, $\mathrm{Ag}$ and $\mathrm{Au}$ are assumed to have full occupancy in our 11-BM and NOMAD refinements. Pearson-VII peaks were used to model the $\mathrm{Ba}_{2} \mathrm{AgIO}_{6}$ and $\mathrm{Ba}_{2} \mathrm{AuIO}_{6}$ XRD peaks because anisotropic broadening was observed (SI ??).

Table S1: Experimental details of crystal structure determination from NOMAD PDF analysis. The errors listed are the statistical errors from the fits. These only varied slightly from the XRD refinements.

\begin{tabular}{lll}
$\begin{array}{l}\text { Formula } \\
\text { Weight }\end{array}$ & $\mathrm{Ba}_{2} \mathrm{AuIO}_{6}$ & $\mathrm{Ba}_{2} \mathrm{AgIO}_{6}$ \\
\hline Space group & $P 2_{1} / c$ & $P 2_{1} / c$ \\
Temperature $(\mathrm{K})$ & 298 & 298 \\
a $(\AA)$ & $6.02(2)$ & $5.931(12)$ \\
b $(\AA)$ & $5.986(16)$ & $6.011(8)$ \\
c $(\AA)$ & $10.48(4)$ & $10.282(17)$ \\
$\beta$ & $126.71(18)$ & $124.19(11)$ \\
Crystallite size $(\mathrm{nm})$ & $5.1(4)$ & $6.4(4)$ \\
$Q_{\text {max }}\left(\AA^{-1}\right)$ & 40 & 40 \\
\# ref. param. & 27 & 27 \\
Constraints & 120 & 119 \\
Overall scale factor & $1.00(4)$ & $0.90(4)$ \\
Linear corr. factor & $1.86(4)$ & $1.76(14)$ \\
Neutron reduced $\chi^{2}$ & 0.10216 & 0.106748 \\
Neutron $R_{w}$ & 0.512056 & 0.466248
\end{tabular}




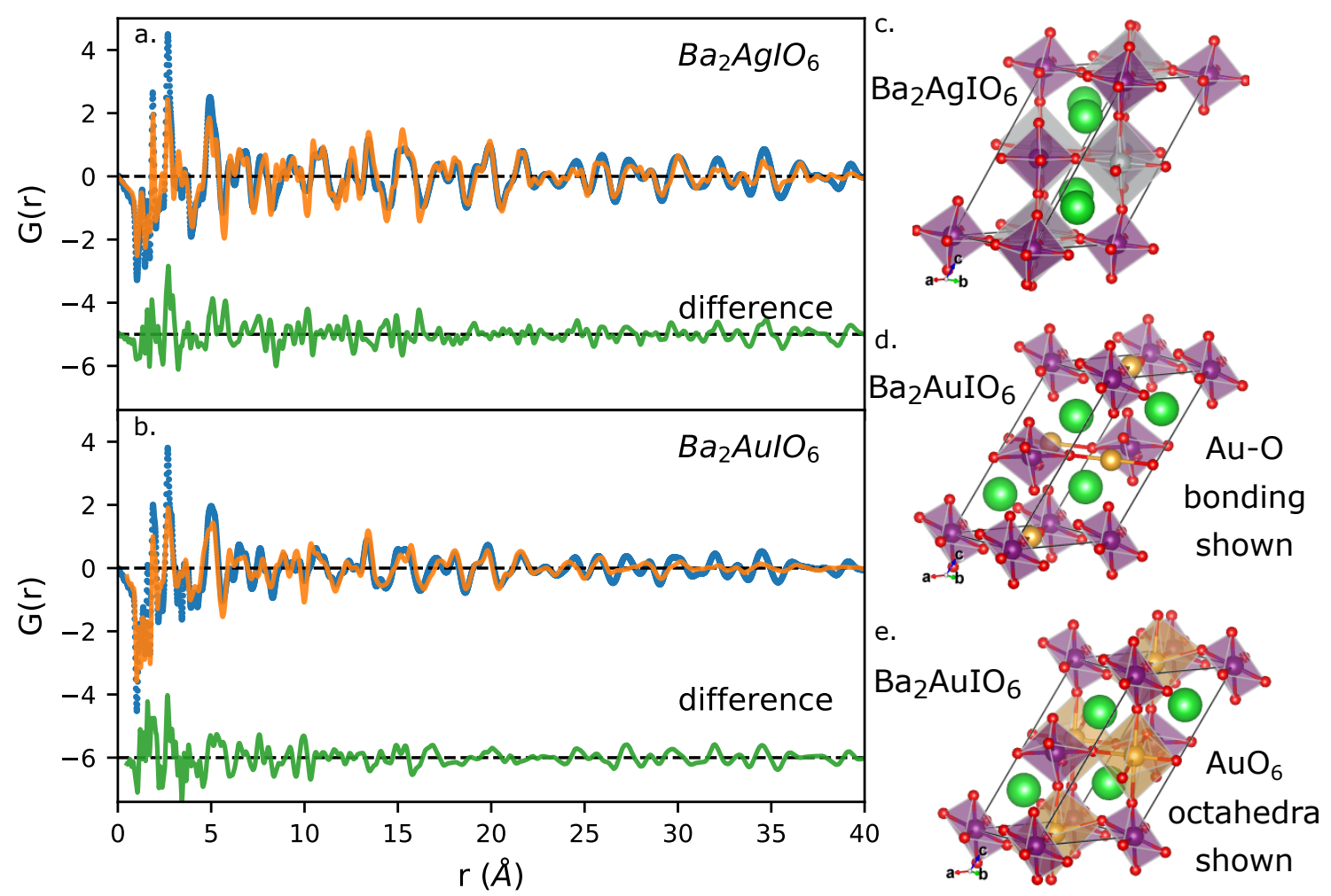

Figure S2: Fitted neutron PDF data for $\mathrm{Ba}_{2} \mathrm{AgIO}_{6}$ (a) and $\mathrm{Ba}_{2} \mathrm{AuIO}_{6}$ (c) and the structures of $\mathrm{Ba}_{2} \mathrm{AgIO}_{6}$ (b) and $\mathrm{Ba}_{2} \mathrm{AuIO}_{6}$ (d and e) thereby determined. Both $\mathrm{Ba}_{2} \mathrm{AgIO}_{6}$ and $\mathrm{Ba}_{2} \mathrm{AuIO}_{6}$ samples contained -OH defects, as shown by the negative peaks between 1 and $1.8 \AA$. In the $F m \overline{3} m$ structure of $\mathrm{Ba}_{2} \mathrm{NaIO}_{6}$ (??), the only degree of freedom is displacement of the only oxygen atom (red) on a line between $\mathrm{X}(\mathrm{Na})$ and $\mathrm{Y}(\mathrm{I})$ sites. There was no way, for $\mathrm{X}=\mathrm{Ag}$ (silver) or $\mathrm{Au}$ (gold), to obtain reasonable bond lengths in $\mathrm{G}(\mathrm{r}$ ) with this constraint. In the monoclinic structure, Ba (green) and the three oxygens (red) are allowed to move in the $\mathrm{x}, \mathrm{y}$, and $\mathrm{z}$ directions with all other sites fixed. For $\mathrm{X}=\mathrm{Ag}$, slight tilts of the $\left(\mathrm{IO}_{6}\right)^{5-}$ and $\left(\mathrm{AgO}_{6}\right)^{-11}$ octahedra occur. The $\mathrm{Ag}-\mathrm{O}$ bond in the $+\mathrm{z}$ direction is elongated compared to the other two unique Ag-O bonds. In $\mathrm{Ba}_{2} \mathrm{AuIO}_{6}$, the $\mathrm{O} 1$ site moves closer to $\mathrm{Ba}$ and away from $\mathrm{Au}$. While an octahedron may still be drawn (e), this allows the bonding around $\mathrm{Au}$ to be linear (d), as is most common for $\mathrm{Au}^{+}$. 
Table S2: Experimental atomic coordinates and isotropic displacement parameters. The $\mathrm{x}$ and y-coordinates of $\mathrm{O} 1$ in $\mathrm{Ba}_{2} \mathrm{AuIO}_{6}$ have a correlation of 0.89 in the PDF refinement. All other correlations were significantly smaller. $U_{e q}=\frac{B_{e q}}{2 \pi^{2}}$. All $B_{e q}$ are in $\AA^{2}$. For each structure, all oxygen atoms were constrained to have the same $B_{e q}$.

\begin{tabular}{llllll}
\multicolumn{5}{c}{$\mathrm{Ba}_{2} \mathrm{AgIO}_{6}$, neutron PDF } \\
Atom & Wyckoff & $\mathrm{x}$ & $\mathrm{y}$ & $\mathrm{z}$ & $B_{e q}$ \\
\hline $\mathrm{Ba}$ & $4 \mathrm{e}$ & $0.283(4)$ & $0.491(4)$ & $0.259(3)$ & $0.60(11)$ \\
$\mathrm{Ag}$ & $2 \mathrm{~d}$ & $1 / 2$ & 0 & $1 / 2$ & $1.2(2)$ \\
$\mathrm{I}$ & $2 \mathrm{a}$ & 0 & 0 & 0 & $0.40(16)$ \\
$\mathrm{O}$ & $4 \mathrm{e}$ & $0.221(4)$ & $0.757(4)$ & $0.018(2)$ & $0.48(4)^{\mathrm{c}}$ \\
$\mathrm{O}$ & $4 \mathrm{e}$ & $0.245(4)$ & $0.197(3)$ & $-0.007(2)$ & $0.48(4)^{\mathrm{c}}$ \\
$\mathrm{O}$ & $4 \mathrm{e}$ & $0.200(4)$ & $0.031(4)$ & $0.2142(16)$ & $0.48(4)^{\mathrm{c}}$ \\
\hline \multicolumn{5}{c}{$\mathrm{Ba}_{2} \mathrm{AuIO}_{6}$, neutron PDF } \\
$\mathrm{Atom}$ & $\mathrm{Wyckoff}$ & $\mathrm{x}$ & $\mathrm{y}$ & $\mathrm{z}$ & $B_{e q}$ \\
\hline $\mathrm{Ba}$ & $4 \mathrm{e}$ & $0.252(8)$ & $0.534(5)$ & $0.282(3)$ & $1.0(3)$ \\
$\mathrm{Au}$ & $2 \mathrm{~d}$ & $1 / 2$ & 0 & $1 / 2$ & $1.0(2)$ \\
$\mathrm{I}$ & $2 \mathrm{a}$ & 0 & 0 & 0 & $1.0(3)$ \\
$\mathrm{O}$ & $4 \mathrm{e}$ & $0.285(6)$ & $0.792(5)$ & $0.088(3)$ & $1.17(13)^{\mathrm{c}}$ \\
$\mathrm{O}$ & $4 \mathrm{e}$ & $0.230(6)$ & $0.222(4)$ & $-0.016(4)$ & $1.17(13)^{\mathrm{c}}$ \\
$\mathrm{O}$ & $4 \mathrm{e}$ & $0.236(8)$ & $0.006(6)$ & $0.211(3)$ & $1.17(13)^{\mathrm{c}}$
\end{tabular}
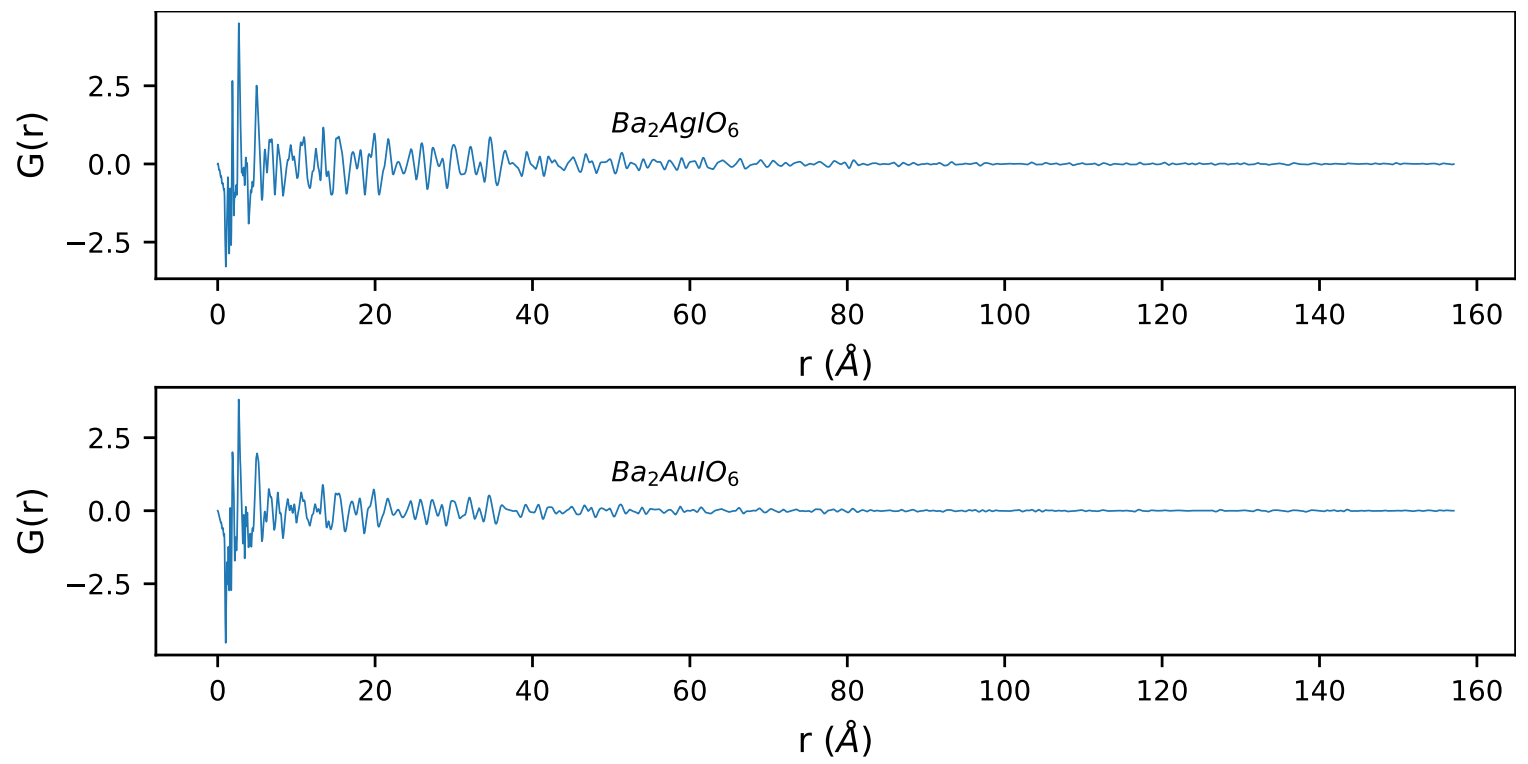

Figure S3: The full $\mathrm{G}(\mathrm{r})$ spectra show neutron correlation lengths $<7 \mathrm{~nm}$ for $\mathrm{Ba}_{2} \mathrm{AgIO}_{6}$ and $\mathrm{Ba}_{2} \mathrm{AuIO}_{6}$. 
Table S3: Experimental phases included and bond lengths. The XRD bond lengths were measured by assuming the neutron PDF atomic positions and then allowing the lattice constant and $\beta$ to refine. The XRD-derived bond lengths are well-within the error of the PDF-derived bond lengths. Consequently, while the XRD-derived lattice constants are most accurate, the PDF-derived atomic positions remain accurate for both.

\begin{tabular}{|c|c|c|c|c|c|c|c|c|}
\hline & & & $\mathrm{Ba}_{2} \mathrm{~A}_{1}$ & $\mathrm{uIO}_{\mathrm{t}}$ & 6 , neutron & & & \\
\hline & & Phase & & $\mathrm{SF}$ & & I distance & & \\
\hline & & $\mathrm{Ba}_{2} \mathrm{Al}_{1}$ & $\mathrm{IO}_{6}$ & 0.9 & & & & \\
\hline & & $\mathrm{OH} 1$ & & 0.0 & & 12(9) $\AA$ & & \\
\hline & & OH 2 & & 0.0 & & $19(12) \AA$ & & \\
\hline & & $\mathrm{OH} 3$ & & 0.0 & & $51(15) \AA$ & & \\
\hline & & $\mathrm{OH} 4$ & & 0.0 & & (2) $\AA$ & & \\
\hline & & & $\mathrm{Ba}_{2} \mathrm{~A}$ & $\mathrm{gIO}_{\mathrm{t}}$ & 6 , neutron & $\mathrm{DF}$ & & \\
\hline & & Phase & & $\mathrm{SF}$ & & I distance & & \\
\hline & & $\mathrm{Ba}_{2} \mathrm{~A}_{\xi}$ & $\mathrm{IO}_{6}$ & 0.8 & & & & \\
\hline & & $\mathrm{BaCO}$ & & 0.0 & $69(16)$ & & & \\
\hline & & $\mathrm{OH} 1$ & & 0.0 & & ( $(2) \AA$ & & \\
\hline & & OH 2 & & 0.0 & & $7(2) \AA$ & & \\
\hline & & $\mathrm{OH} 3$ & & 0.0 & & $3(7) \AA$ & & \\
\hline Bond & $\begin{array}{l}\mathrm{Ba}_{2} \mathrm{AuIO}_{6} \\
\mathrm{XRD}(\AA)\end{array}$ & $\mathrm{PDF}(\AA)$ & Bon & & $\begin{array}{l}\mathrm{Ba}_{2} \mathrm{AgIO}_{6} \\
\mathrm{XRD}(\AA)\end{array}$ & $\operatorname{PDF}(\AA)$ & Bond & $\begin{array}{l}\mathrm{Ba}_{2} \mathrm{NaIO}_{6} \\
\mathrm{XRD}(\AA)\end{array}$ \\
\hline $\mathrm{Ba}-\mathrm{O} 1$ & 2.63 & $2.65(14)$ & $\mathrm{Ba}-\mathrm{C}$ & & 2.78 & $2.78(9)$ & $\mathrm{Ba}-\mathrm{O}$ & $2.951867(62)$ \\
\hline Ba-O1 & 2.69 & $2.68(23)$ & $\mathrm{Ba}-\mathrm{C}$ & & 2.79 & $2.80(7)$ & $\mathrm{CN}=12$ & \\
\hline $\mathrm{Ba}-\mathrm{O} 2$ & 2.66 & $2.69(15)$ & $\mathrm{Ba}-\mathrm{C}$ & & 2.80 & $2.80(18)$ & & \\
\hline $\mathrm{Ba}-\mathrm{O} 2$ & 2.83 & $2.8(3)$ & $\mathrm{Ba}-\mathrm{C}$ & & 2.81 & $2.80(10)$ & & \\
\hline $\mathrm{Ba}-\mathrm{O} 3$ & 2.91 & $2.91(11)$ & $\mathrm{Ba}-\mathrm{C}$ & & 2.86 & $2.88(16)$ & & \\
\hline $\mathrm{Ba}-\mathrm{O} 2$ & 2.97 & $2.9(3)$ & $\mathrm{Ba}-\mathrm{C}$ & & 2.95 & $2.93(9)$ & & \\
\hline $\mathrm{Ba}-\mathrm{O} 3$ & 2.97 & $3.00(14)$ & Ba- - & & 3.07 & $3.04(8)$ & & \\
\hline Ba-O3 & 3.01 & $3.04(15)$ & $\mathrm{Ba}-\mathrm{C}$ & & 3.09 & $3.12(17)$ & & \\
\hline $\mathrm{Ba}-\mathrm{O} 3$ & 3.23 & $3.23(10)$ & $\mathrm{Ba}-\mathrm{C}$ & & 3.17 & $3.16(10)$ & & \\
\hline Ba-O1 & 3.24 & $3.27(15)$ & $\mathrm{Ba}-\mathrm{C}$ & & 3.27 & $3.25(09)$ & & \\
\hline $\mathrm{Ba}-\mathrm{O} 2$ & 3.54 & $3.57(16)$ & Ba- $\mathrm{C}$ & & 3.26 & $3.28(7)$ & & \\
\hline Ba-O1 & 3.8 & $3.8(3)$ & $\mathrm{Ba}-\mathrm{C}$ & & 3.29 & $3.31(17)$ & & \\
\hline $\mathrm{Au}-\mathrm{O} 2$ & 2.2513 & $2.26(7)$ & $\mathrm{Ag}-\mathrm{C}$ & & 2.34 & $2.34(4)$ & $\mathrm{Na}-\mathrm{O}$ & $2.2600(14)$ \\
\hline $\mathrm{Au}-\mathrm{O} 3$ & 2.4541 & $2.44(12)$ & $\mathrm{Ag}-\mathrm{C}$ & & 2.35 & $2.34(4)$ & $\mathrm{CN}=6$ & \\
\hline $\mathrm{Au}-\mathrm{O} 1$ & 2.6248 & $2.65(7)$ & $\mathrm{Ag}-\mathrm{C}$ & & 2.43 & $2.44(7)$ & & \\
\hline I-O3 & 1.7871 & $1.77(13)$ & I-O3 & & 1.82 & $1.83(6)$ & $\mathrm{I}-\mathrm{O}$ & $1.9071(14)$ \\
\hline $\mathrm{I}-01$ & 1.8623 & $1.86(11)$ & I-O1 & & 1.90 & $1.91(4)$ & $\mathrm{CN}=6$ & \\
\hline I-02 & 1.9865 & $2.00(7)$ & $\mathrm{I}-\mathrm{O} 2$ & & 1.92 & $1.91(4)$ & & \\
\hline
\end{tabular}




\section{$\mathrm{Ba}_{2} \mathrm{NaIO}_{6}$ refinement information}

Table S4: Experimental details of crystal structure determination (from XRD for $\mathrm{Ba}_{2} \mathrm{NaIO}_{6}$ ), from neutron PDF data for $\mathrm{Ba}_{2} \mathrm{AgIO}_{6}$ and $\mathrm{Ba}_{2} \mathrm{AuIO}_{6}$ ), The errors listed are the statistical errors from the fits. The $\mathrm{x}$ and $\mathrm{y}$-coordinates of $\mathrm{O} 1$ in $\mathrm{Ba}_{2} \mathrm{AuIO}_{6}$ have a correlation of 0.89 in the PDF refinement.

\begin{tabular}{ll} 
Formula & $\mathrm{Ba}_{2} \mathrm{NaIO}_{6}$ \\
Weight & \\
\hline Space group & $F m \overline{3} m$ \\
Temperature $(\mathrm{K})$ & 298 \\
a $(\AA)$ & $8.3342(8)$ \\
Unit cell volume $\left(\AA^{3}\right)$ & $578.72(16)$ \\
Cell formula units $\mathrm{Z}$ & 4 \\
Density $\left(\mathrm{g} / \mathrm{cm}^{3}\right)$ & $5.973(2)$ \\
Wavelength $(\AA)$ & 0.457856 \\
Crystallite size $(\mathrm{nm})$ & $528(12)$ \\
$2 \theta$ min $\left(^{\circ}\right)$ & 0.5 \\
$2 \theta$ max $\left({ }^{\circ}\right)$ & 50 \\
increment in $2 \theta$ & 0.001 \\
$\#$ XRD data points & 49574 \\
$\#$ variables & 53 \\
$R_{P}(\%)$ & 7.30 \\
$R_{W}(\%)$ & 9.55 \\
$R_{W e x p e c t e d}(\%)$ & 3.35 \\
$R_{B r a g g}$ & 1.382 \\
Goodness of fit & 2.85 \\
ICSD No. & \\
Purity $(\mathrm{XRD})$ & $91.39 \% \mathrm{Ba}_{2} \mathrm{NaIO}_{6}$, \\
& $8.61 \% \mathrm{BaCO}_{3}$, \\
&
\end{tabular}


Table S5: Experimental atomic coordinates and isotropic displacement parameters for $\mathrm{Ba}_{2} \mathrm{NaIO}_{6}$ from 11-BM XRD data. $U_{e q}=\frac{B_{e q}}{2 \pi^{2}} \cdot U_{e q}=1 / 3$ trace of orthogonalized U tensor. All B are in $\AA^{2}$. All $\mathrm{U}$ are in $100 \times \stackrel{\circ}{A}^{2}$.

\begin{tabular}{llllll}
\multicolumn{5}{c}{$\mathrm{Ba}_{2} \mathrm{NaIO}_{6}, \mathrm{XRD}$} \\
Atom & $\mathrm{x}$ & $\mathrm{y}$ & $\mathrm{z}$ & $B_{e q}$ & $U_{e q}$ \\
\hline $\mathrm{Ba}$ & $1 / 4$ & $1 / 4$ & $1 / 4$ & $0.56(9)$ & $0.71(11)$ \\
$\mathrm{Na}$ & $1 / 2$ & $1 / 2$ & $1 / 2$ & $0.89(9)$ & $1.13(11)$ \\
$\mathrm{I}$ & 0 & 0 & 0 & $0.33(9)$ & $0.42(11)$ \\
$\mathrm{O}$ & $0.22883(17)$ & 0 & 0 & $0.94(9)$ & $1.19(11)$
\end{tabular}

\section{Raman peak details}

When an as-pressed $\mathrm{Ba}_{2} \mathrm{AgIO}_{6}$ pellet was illuminated, the Raman signal intensity stayed consistent and there were few signs of sample damage associated with the laser. After the same sample was heated to $90^{\circ} \mathrm{C}$ for $10 \mathrm{~h}$, Raman signal intensities were noticeably lower after 1 minute of illumination and dark spots from laser damage were apparent. The $\mathrm{Ba}_{2} \mathrm{AuIO}_{6}$ was more susceptible to beam-induced degradation but, even when the laser was initially turned on, the signal was very weak.

Table S6: Locations and attribution of Raman peaks in various double perovskites (in $\mathrm{cm}^{-1}$ ). These peaks were decomposed from the $514 \mathrm{~nm}$ spectra.

\begin{tabular}{lccc} 
& $A_{1 g}$ & $E_{g}$ & $T_{2 g}$ \\
\hline $\mathrm{Ba}_{2} \mathrm{NaIO}_{6}$ & 716 & 635 & 427 \\
$\mathrm{Ba}_{2} \mathrm{AgIO}_{6}$ & 669 & 600 & 483,417 \\
$\mathrm{Sr}_{2} \mathrm{NaIO}_{6}{ }^{7}$ & 725 & 649 & 454,439 \\
$\mathrm{Ca}_{2} \mathrm{NaIO}_{6}{ }^{7}$ & 721 & 644,622 & $453,438,427$
\end{tabular}




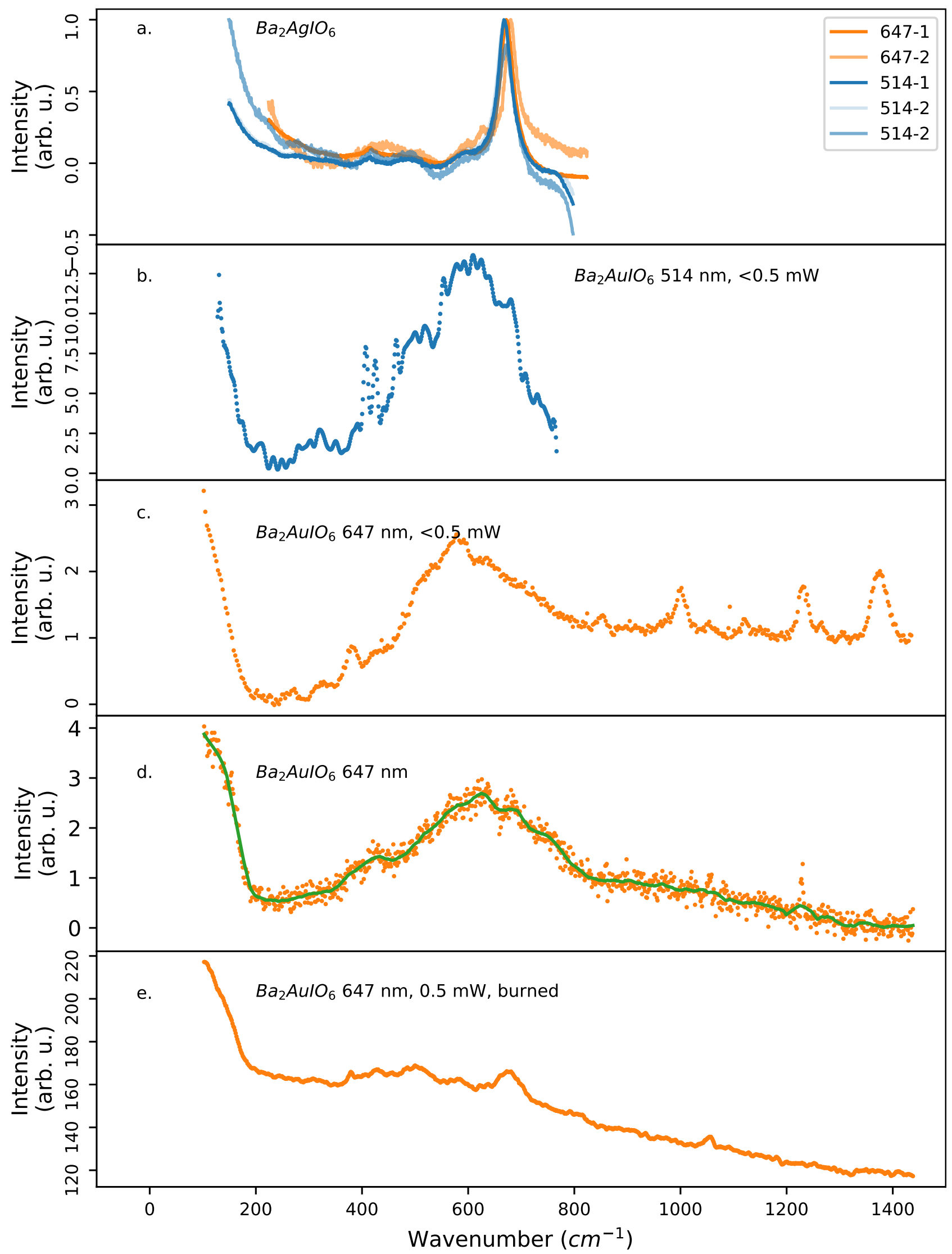

Figure S4: The $\mathrm{Ba}_{2} \mathrm{AuIO}_{6}$ and $\mathrm{Ba}_{2} \mathrm{AgIO}_{6}$ samples showed fairly consistent Raman scattering using both 514 and $647 \mathrm{~nm}$ lasers. The spectfum of a "burnt" region of a $\mathrm{Ba}_{2} \mathrm{AuIO}_{6}$ sample (e) is distinguishable from "unburnt," low-power measurements. 


\section{Heat Capacity}
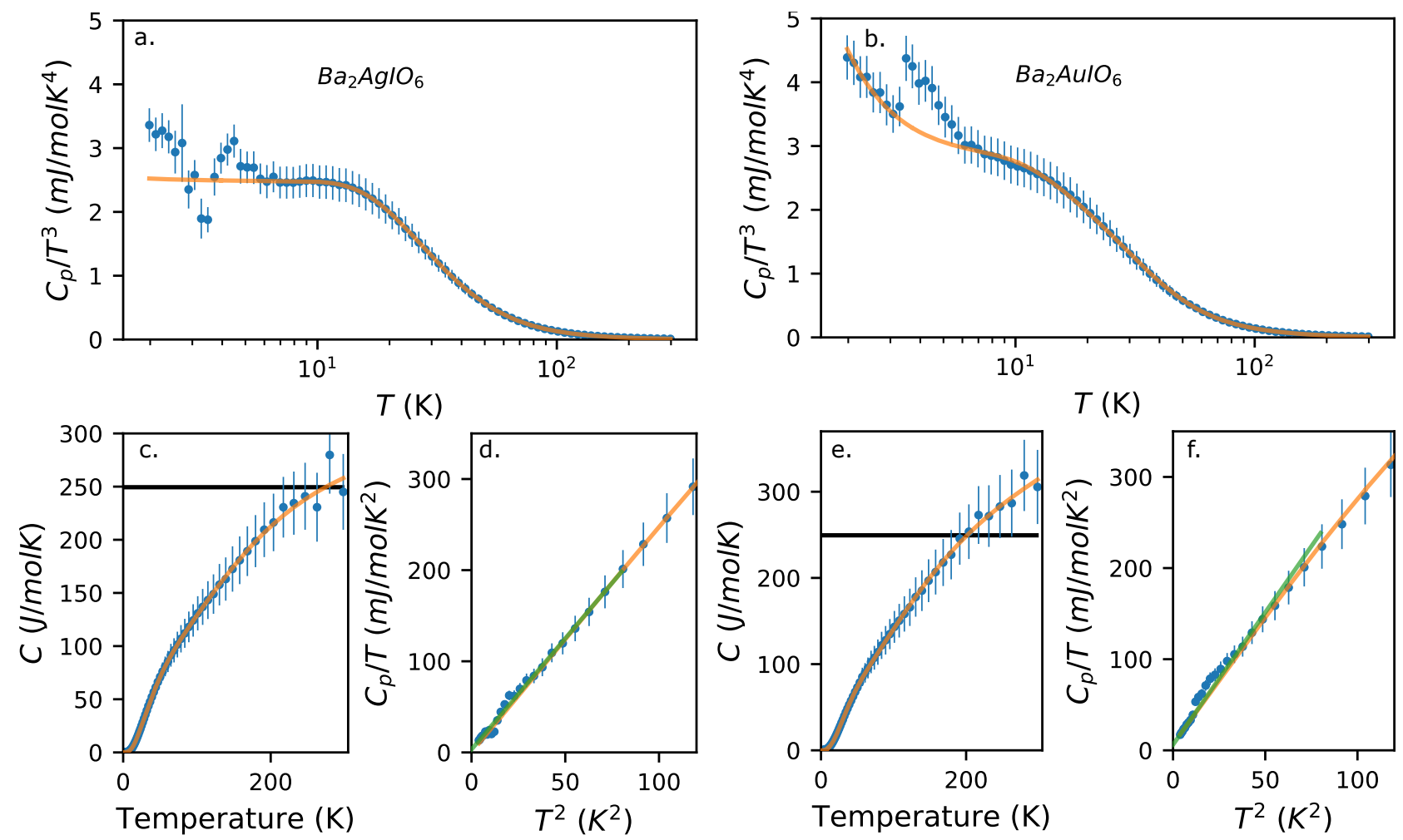

Figure S5: Heat capacity data for $\mathrm{Ba}_{2} \mathrm{AgIO}_{6}$ (a-c) and $\mathrm{Ba}_{2} \mathrm{AuIO}_{6}$ (d-f) show relatively small electron contributions. This data was adjusted to account for 2 wt. $\%$ water and $\mathrm{BaCO}_{3}$ secondary phase $\left(8.7\right.$ wt. $\%$ for $\mathrm{Ba}_{2} \mathrm{AgIO}_{6}, 23$ wt. $\%$ for $\mathrm{Ba}_{2} \mathrm{AuIO}_{6}$ ). For both samples, an anomaly from $3 \mathrm{~K}$ to $5 \mathrm{~K}$ was observed, which is likely not intrinsic to the sample. A linear fit to the $C_{p} / T$ vs. $T^{2}$ plots in c and f showed $\gamma=0.3 \mathrm{~mJ} / \mathrm{molK}^{2}$ for $\mathrm{Ba}_{2} \mathrm{AgIO}_{6}$ and $7.5 \mathrm{~mJ} / \mathrm{molK}$ for $\mathrm{Ba}_{2} \mathrm{AuIO}_{6}$. This is on par with transition metals like $\mathrm{Pt}$ and $\mathrm{Ni}$ but is an order of magnitude larger than those observed for $\mathrm{Au}$ and $\mathrm{Ag} .{ }^{[8}$ Since the heat capacity rises above the Dulong and Petit limit, $C_{V}$ is not an appropriate approximation of $C_{P}$ in this case.

The specific heat capacity of $\mathrm{Ba}_{2} \mathrm{AgIO}_{6}$ and $\mathrm{Ba}_{2} \mathrm{AuIO}_{6}$ were measured to determine if subsequent phase transitions to lower-symmetry structures occur below room-temperature. None were observed. The data was adjusted to account for $\mathrm{BaCO}_{3}$ inclusions (minimal effect, corrected using the XRD-measured wt. \% using Gurevich et al. ${ }^{[}$) and up to 2 wt. \% water (slightly greater effect, corrected using a measured amount in $\mathrm{Ba}_{2} \mathrm{AgIO}_{6}$ using Shulman et al.10) No low-temperature phase transitions were observed. The anomalies between 3 and $5 \mathrm{~K}$ are related to helium interacting with the powdered sample and are not due to the 
material, itself (and were excluded from the fits). For both samples, t, especially $\mathrm{Ba}_{2} \mathrm{AuIO}_{6}$, the heat capacity rose slightly above the Dulong and Petit limit, indicating that $C_{V}$ is not an appropriate approximation of $C_{P}$ for these materials around room-temperature. This was accounted for using the Nernst-Lindemann relation, $C_{p}-C_{v}=\left(\frac{V \beta^{2}}{\kappa_{T}}\right) T=A C_{p}^{2} T$ where $V$ is volume, $\kappa_{T}$ is the isothermal compressibility, and $\beta$ is the volume expansion coefficient. 11112 $A$ is treated as a constant, which is true for a wide range of materials such as copper $\left(4.0 \times 10^{-6} \mathrm{~mol} / J\right.$ to $3.9 \times 10^{-6} \mathrm{~mol} / J$ from $100 \mathrm{~K}$ to $\left.800 \mathrm{~K}\right)$ and tungsten $\left(3.5 \times 10^{-6} \mathrm{~mol} / \mathrm{J}\right.$ to $3.6 \times 10^{-6} \mathrm{~mol} / J$ from 100 to $\left.1300 \mathrm{~K}\right) \stackrel{11}{ }$ Both $\mathrm{Ba}_{2} \mathrm{AgIO}_{6}$ and $\mathrm{Ba}_{2} \mathrm{AuIO}_{6}$ were fit using three Debye oscillators, as shown in Equation (1), using the parameters shown in Table S7.

$$
\begin{array}{r}
\Theta_{D}\left(T, \theta_{D}\right)=9 R\left(\frac{T}{\theta_{D}}\right)^{3} \int_{0}^{\theta_{D} / T} \frac{x^{4} e^{-x}}{\left(1-e^{-x}\right)^{2}} d x \\
C_{v}=\gamma T+N_{1} \Theta_{D, 1}\left(T, \theta_{D, 1}\right)+N_{2} \Theta_{D, 2}\left(T, \theta_{D, 2}\right)+N_{3} \Theta_{D, 3}\left(T, \theta_{D, 3}\right) \\
C_{p}=\frac{1-\sqrt{1-4 A T C_{v}}}{2 A T}
\end{array}
$$

Reducing the number of oscillators resulted in unrealistic molar sums of oscillator contributions $\left(\sum N_{i} \sim 10\right.$ for $\left.\mathrm{Ba}_{2} \mathrm{XIO}_{6}\right)$. Using three Debye oscillators, the sum of the oscillators was 12.8 for $\mathrm{Ba}_{2} \mathrm{AgIO}_{6}$ and 13 for $\mathrm{Ba}_{2} \mathrm{AuIO}_{6}$, which are relatively close to 10 . One would expect the oxygen atoms to have a significantly higher Debye temperature than the other atoms because it has a much lower mass. The error in this oxygen-related Debye temperature is significantly higher than for the other measurements since they play less of a role at the temperatures measured. 
Table S7: Heat capacity data fitting parameters. When $\gamma$ was calculated using the intercept of $C_{p} / T$ vs. $T^{2}$, the error $(4 \mathrm{~mJ} / \mathrm{K})$ was significantly smaller compared to the full fit (error $19 \mathrm{~mJ} / \mathrm{K}$ ), since this is the plot most sensitive to $\gamma$. Therefore, we report the value $\gamma$ from our fit and the error from the intercept for $\mathrm{Ba}_{2} \mathrm{AgIO}_{6}$ since our fit value was within the error bar of the intercept-derived $\gamma$. Both are reported for $\mathrm{Ba}_{2} \mathrm{AuIO}_{6}$ (intercept approach in parentheses). The intercept approach is expected to be more accurate. One potential unaccounted reason for $\sum_{\text {all }} N_{i} \neq 10$ is changes in the $\mathrm{BaCO}_{3}$ content over time. Changing the weight fraction in $\mathrm{Ba}_{2} \mathrm{AgIO}_{6}$ of $\mathrm{BaCO}_{3}$ from 18 wt. $\%$ to 8 wt. \% (from an earlier XRD measurement) moves $\sum_{\text {all }} N_{i}$ to include 10 easily but does not significantly change the fit values. Similarly, changing the fraction of $\mathrm{BaCO}_{3}$ from 23 wt. $\%$ to 15 wt. $\%$ does not significantly change the fit values but significantly changes the errors.

\begin{tabular}{ccc} 
& $\mathrm{Ba}_{2} \mathrm{AgIO}_{6}$ & $\mathrm{Ba}_{2} \mathrm{AuIO}_{6}$ \\
\hline$A(\mathrm{~mol} / \mathrm{J})$ & $0 \pm 2 \times 10^{-6}$ & $(1.3 \pm 6.0) \times 10^{-6}$ \\
$\gamma(\mathrm{mJ} / \mathrm{K})$ & $0.4 \pm 3.5$ & $6.8 \pm 1.1(6.2 \pm 0.6)$ \\
$N_{1}$ & $1.9 \pm 0.2$ & $0.4 \pm 0.5$ \\
$\theta_{D, 1}(\mathrm{~K})$ & $124 \pm 4$ & $80 \pm 20$ \\
$N_{2}$ & $3.1 \pm 0.3$ & $4.1 \pm 0.8$ \\
$\theta_{D, 2}(\mathrm{~K})$ & $240 \pm 20$ & $180 \pm 30$ \\
$N_{3}$ & $8 \pm 1$ & $9 \pm 8$ \\
$\theta_{D, 3}(\mathrm{~K})$ & $800 \pm 100$ & $700 \pm 300$ \\
$\sum_{\text {atoms in f.u. }} N_{i}$ & $12.8 \pm 1.9$ & $13 \pm 10$
\end{tabular}

\section{Band Structure}

Relaxing monoclinic $\mathrm{Ba}_{2} \mathrm{AuIO}_{6}$ using Quantum Espresso and fully relativistic PAW PBE pseudopotentials, Au-O bond lengths become $2.22 \AA, 2.21 \AA$, and $2.20 \AA$, which is inconsistent with typical $\mathrm{Au}^{+}$and $\mathrm{Au}^{3+}$ coordinations, which are linear and square planar, respectively. Relaxing monoclinic $\mathrm{Ba}_{2} \mathrm{AuIO}_{6}$ using Elk, which is an all-electron calculation, the Au-O bond lengths become $2.25 \AA, 2.29 \AA$, and $2.30 \AA$, a slightly larger spread but still not fully consistent with typical $\mathrm{Au}^{+}$coordinations. Our experimental Au-O bond lengths were $2.26 \AA$, $2.44 \AA$, and $2.65 \AA$. The Elk-derived I-O bond lengths increased to $1.96 \AA, 1.97 \AA$, and $1.98 \AA$ compared to, experimentally, $1.77 \AA, 1.86 \AA$, and $2.00 \AA$ in monoclinic $\mathrm{Ba}_{2} \mathrm{AuIO}_{6}$. The experimental bond lengths average to $1.88 \AA$, which is in good agreement with the experimental $\mathrm{Ba}_{2} \mathrm{AgIO}_{6}$ and $\mathrm{Ba}_{2} \mathrm{NaIO}_{6} \mathrm{I}-\mathrm{O}$ bond lengths (See Table $\mathrm{S} 3, \sim 1.90 \AA$ and smaller than the average bond length in the Elk-relaxed structure. The importance of distorted octahedra on these band structures suggests that there is something missing in the relativistic 
pseudopotentials and, to a lesser extent, the Elk atomic species description. Whatever gives rise to the asymmetric Au and I sites is likely responsible for the observed band gap in $\mathrm{Ba}_{2} \mathrm{AuIO}_{6}$ and is not well-represented by the pseudopotentials (a source of error). It is clear that the local symmetry of the gold is important to the electronic behavior of $\mathrm{Ba}_{2} \mathrm{AuIO}_{6}$.

Table S8: The Elk-relaxed structure of $\mathrm{Ba}_{2} \mathrm{AuIO}_{6}$ is compared to the experimentallydetermined structure. There were no changes to the lattice parameters but the Ba site shifted slightly closer $(0.3 \AA)$ to the ideal cubic structure at $(0,1 / 2,1 / 4)$, bringing some of the oxygen atoms with it. These are visualized in Figure S9. The O2 site was little-changed during the relaxation, moving $0.1 \AA$, with the $\mathrm{O} 1$ atom moving $0.5 \AA$ and the $\mathrm{O} 3$ atom moving $0.4 \AA$. In the Elk-relaxed structure, $\mathrm{Au}-\mathrm{O}$ bond lengths were $2.27 \AA, 2.30 \AA$, and $2.29 \AA$. The I-O bond lengths were $1.96 \AA, 1.97 \AA$, and $1.96 \AA$. It is very likely that the incorporated $\left(\mathrm{H}_{3} \mathrm{O}_{\mathrm{Au}}{ }^{+}\right)$increases observed the tetrahedral distortions, particularly around $\mathrm{Au}$ sites, due to the polar nature of the $\mathrm{H}_{3} \mathrm{O}^{+}$.

\begin{tabular}{|c|c|c|c|c|c|c|}
\hline \multicolumn{7}{|c|}{$\mathrm{Ba}_{2} \mathrm{AuIO}_{6}\left(\mathrm{SG} 14\right.$, pseudo-orthorhombic $\left.P 2_{1} / n\right)$} \\
\hline & \multicolumn{3}{|c|}{ Elk-relaxed } & \multicolumn{3}{|c|}{ Experimental (PDF and XRD) } \\
\hline a & & $5.96653 \AA$ & & & 5.96 & \\
\hline $\mathrm{b}$ & & $5.98251 \AA$ & & & 5.98 & \\
\hline $\mathrm{c}$ & & $8.45835 \AA$ & & & 8.45 & \\
\hline$\beta$ & & $90.268^{\circ}$ & & & 90 . & \\
\hline Atom & $\mathrm{x}$ & $\mathrm{y}$ & $\mathrm{Z}$ & $\mathrm{x}$ & $\mathrm{y}$ & $\mathrm{Z}$ \\
\hline $\mathrm{Ba}$ & -0.002379 & -0.481027 & -0.241166 & -0.030 & 0.466 & -0.218 \\
\hline $\mathrm{Au}$ & 0 & 0 & 0 & 0 & 0 & 0 \\
\hline I & 0 & 0 & $1 / 2$ & 0 & 0 & $1 / 2$ \\
\hline O1 & 0.228677 & -0.233632 & -0.467194 & 0.197 & -0.208 & -0.412 \\
\hline $\mathrm{O} 2$ & 0.24032 & 0.223765 & 0.492149 & 0.245 & 0.222 & 0.484 \\
\hline O3 & -0.02309 & 0.037942 & -0.269938 & 0.025 & 0.006 & -0.289 \\
\hline
\end{tabular}




\section{Monoclinic $\mathrm{Ba}_{2} \mathrm{XIO}_{6}$ Brillouin Zone}

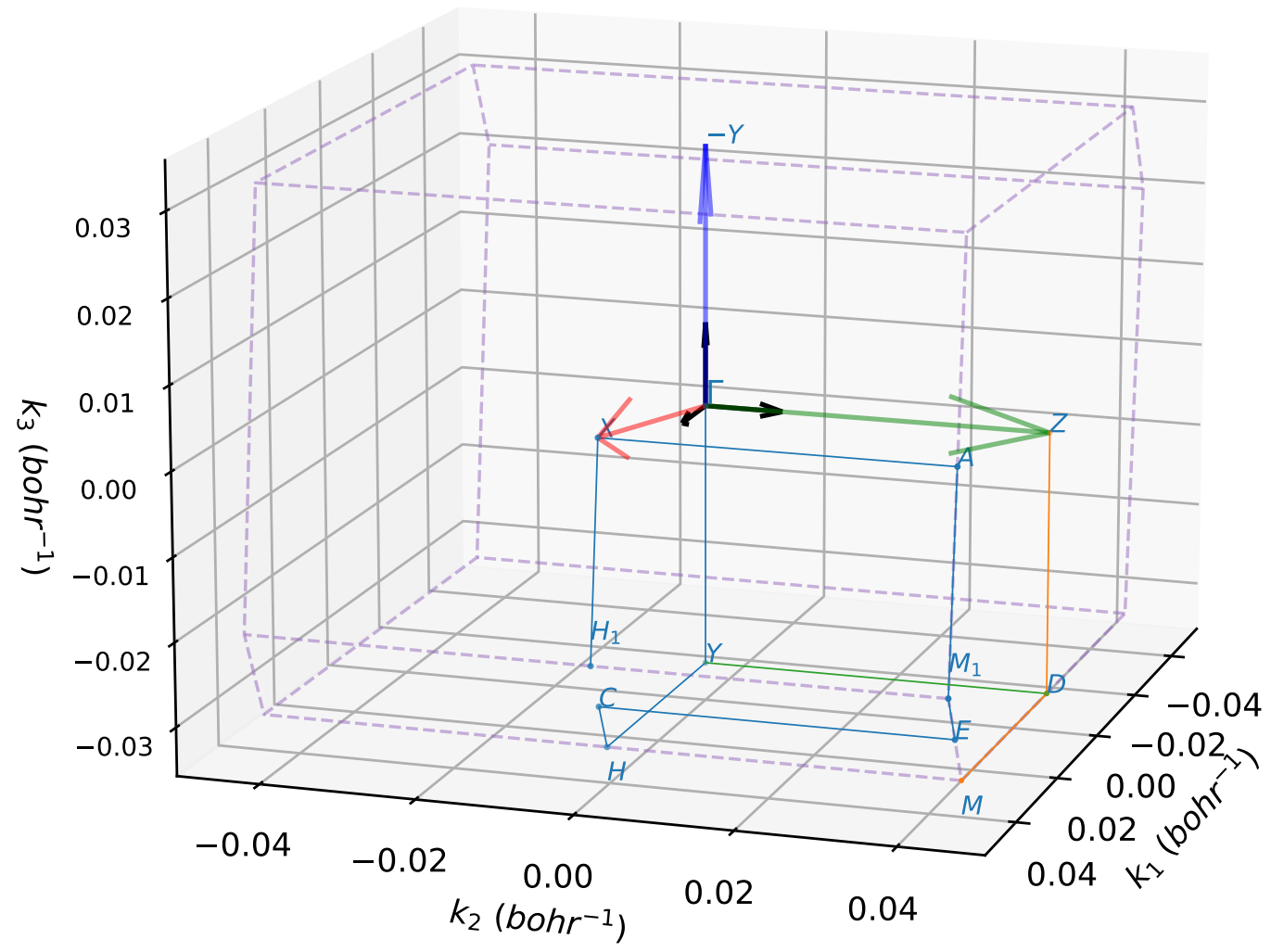

Figure S6: Monoclinic special points, with the monoclinic distortion exaggerated to better show the path through the Brillouin zone. See Figure $\mathrm{S} 7$ for the actual reciprocal space of $\mathrm{Ba}_{2} \mathrm{AuIO}_{6}$. The reciprocal space vectors are shown in red, green, and blue while the $\mathrm{x}, \mathrm{y}$, and $\mathrm{z}$ axes are shown in black. Note that these are plotted according to the crystallographer's convention (no $2 \pi$ ). 


\section{Monoclinic $\mathrm{Ba}_{2} \mathrm{AglO}_{6}$ Brillouin Zone}

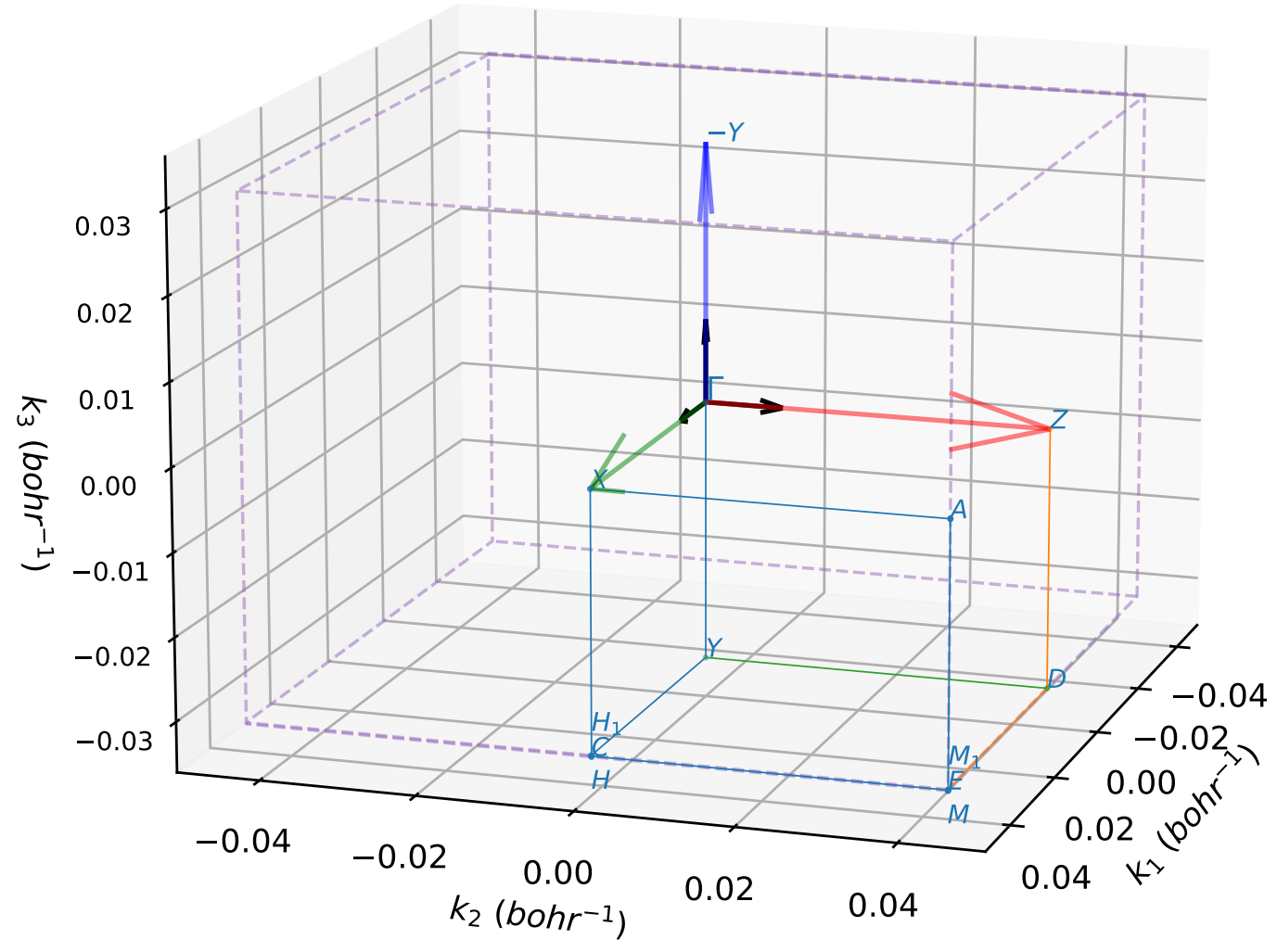

Figure S7: The actual monoclinic special points for $\mathrm{Ba}_{2} \mathrm{AgIO}_{6}$ with the Brillouin zone plotted to scale. In Elk, the reciprocal lattice vectors used, $\left(\overrightarrow{b_{1}}, \overrightarrow{b_{2}}\right.$, and $\left.\overrightarrow{b_{3}}\right)$, are red, green, and blue, respectively. Note that these are plotted according to the crystallographer's convention (no $2 \pi)$. 


\section{Cubic $\mathrm{Ba}_{2} \mathrm{AulO}_{6}$ Brillouin Zone}

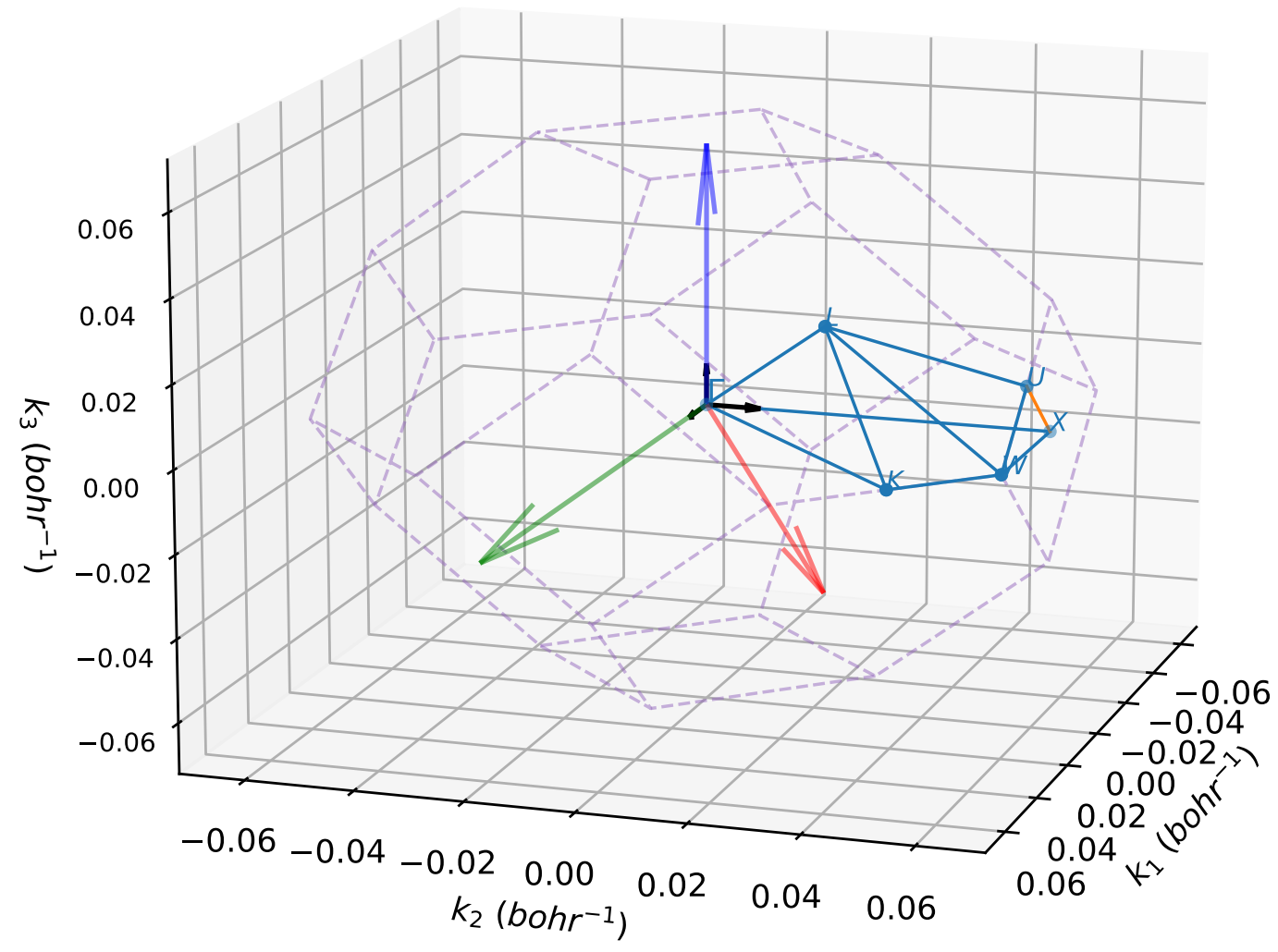

Figure S8: The FCC special points for $\mathrm{Ba}_{2} \mathrm{AuIO}_{6}$ (and $\mathrm{Ba}_{2} \mathrm{AgIO}_{6}$ ) with the Brillouin zone plotted. In Elk, the reciprocal lattice vectors used, $\left(\overrightarrow{b_{1}}, \overrightarrow{b_{2}}\right.$, and $\left.\overrightarrow{b_{3}}\right)$, are red, green, and blue, respectively. Note that these are plotted according to the crystallographer's convention (no $2 \pi)$. 

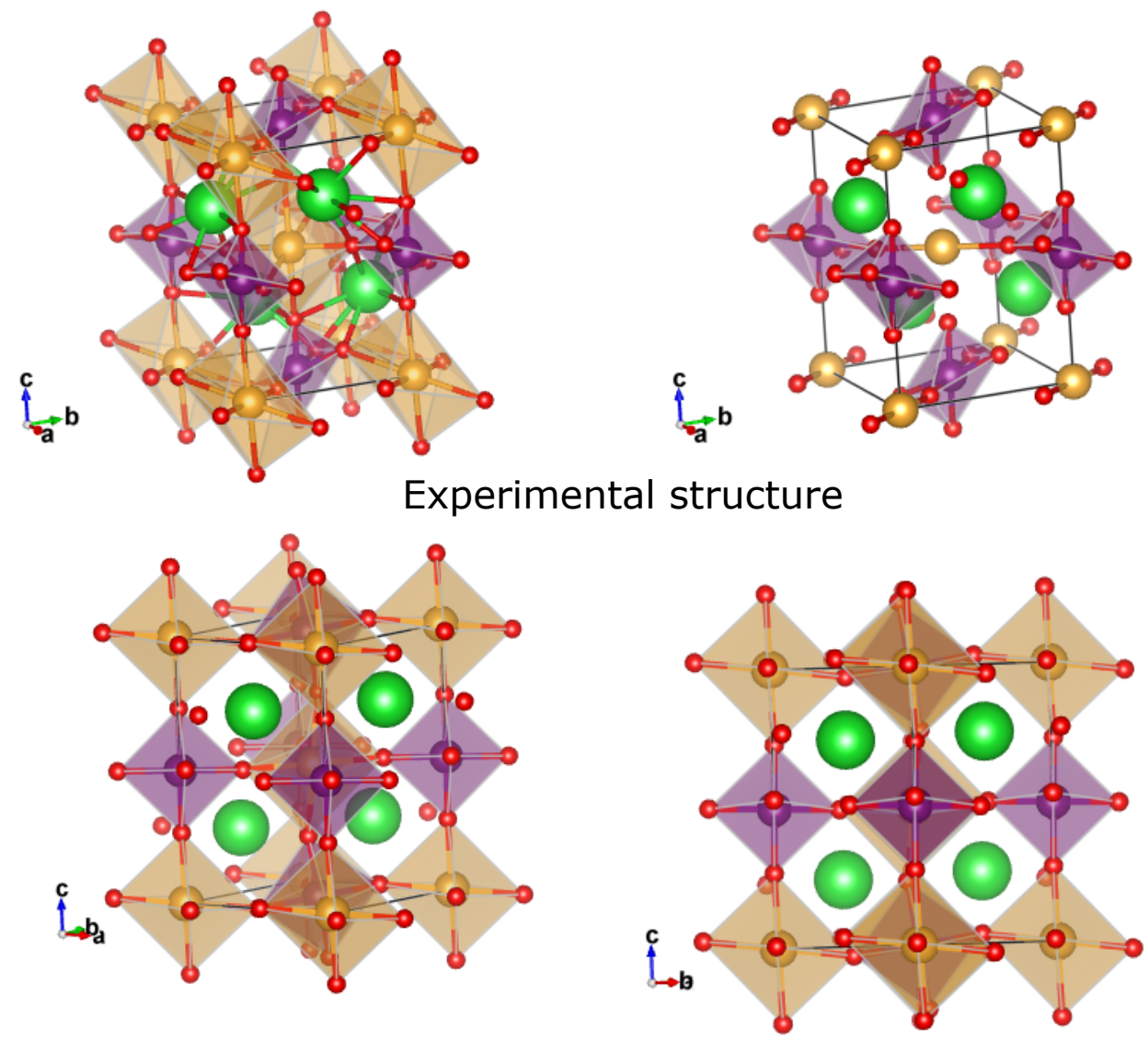

Elk-optimized structure

Figure S9: Visualization of the experimental $\mathrm{Ba}_{2} \mathrm{AuIO}_{6}$ structure (top) to the Elk-relaxed structure. 


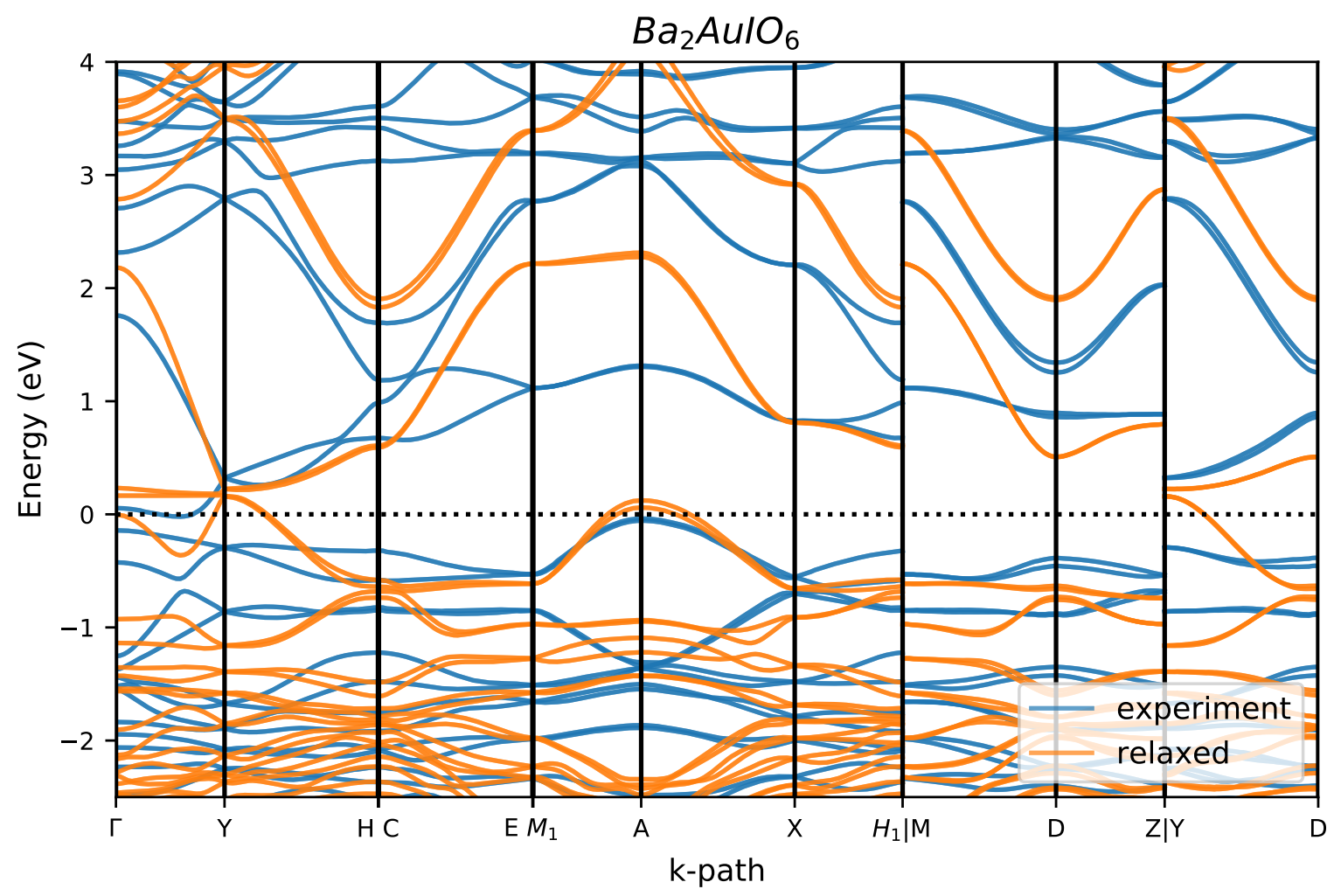

Figure S10: Relaxing the $\mathrm{Ba}_{2} \mathrm{AuIO}_{6}$ using elk removed the gap near $E_{F}$ (making it metallic) and the band crossings between $\mathrm{C}$ and $\mathrm{E}$. There are clear similarities between the two structures. Both of these calculations incorporated spin-orbit coupling. 


\section{Monoclinic $\mathrm{Ba}_{2} \mathrm{AgIO}_{6}$ Brillouin Zone}

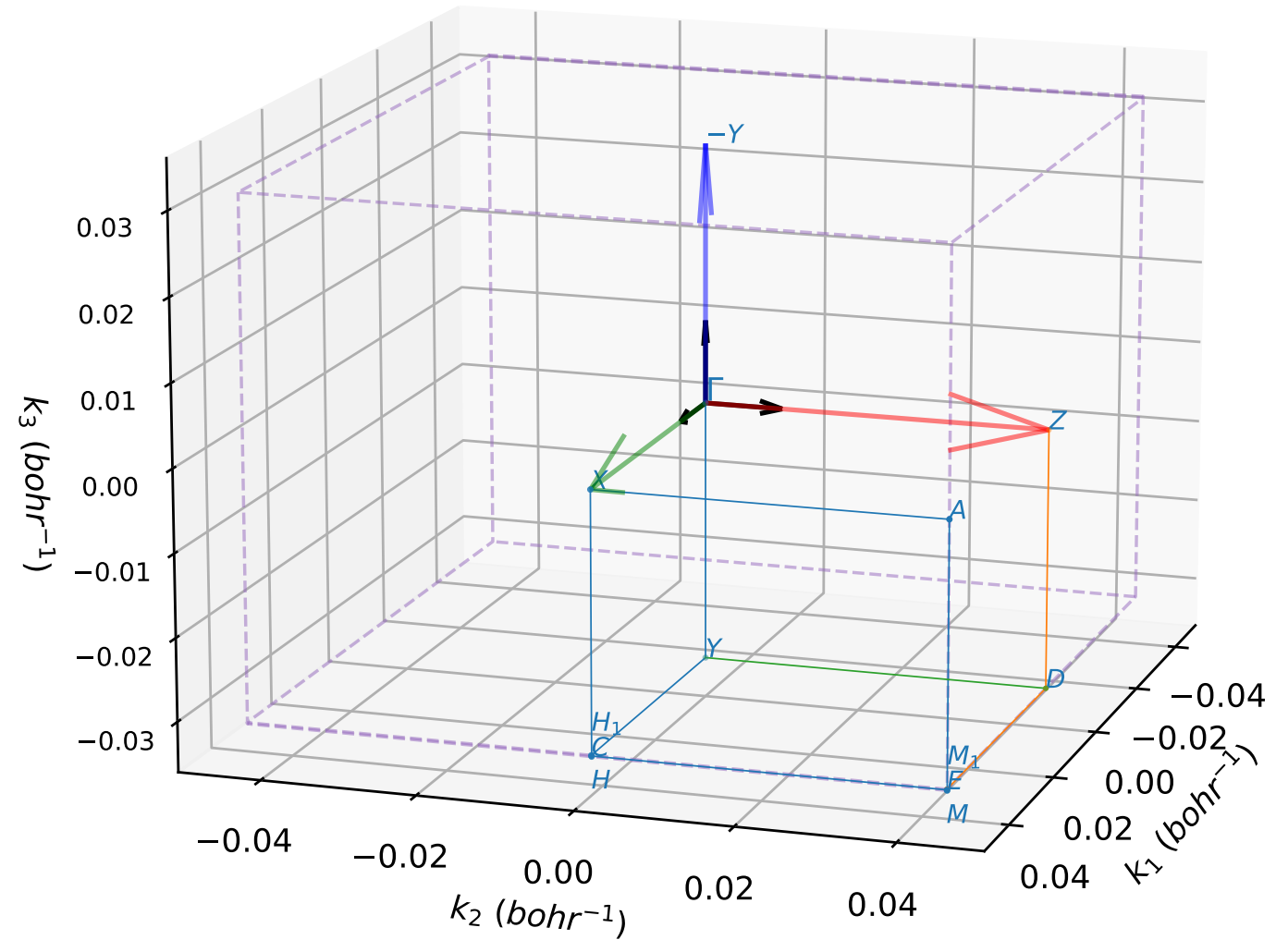

Figure S11: Visualization of the experimental $\mathrm{Ba}_{2} \mathrm{AuIO}_{6}$ structure (top) to the Elk-relaxed structure. 


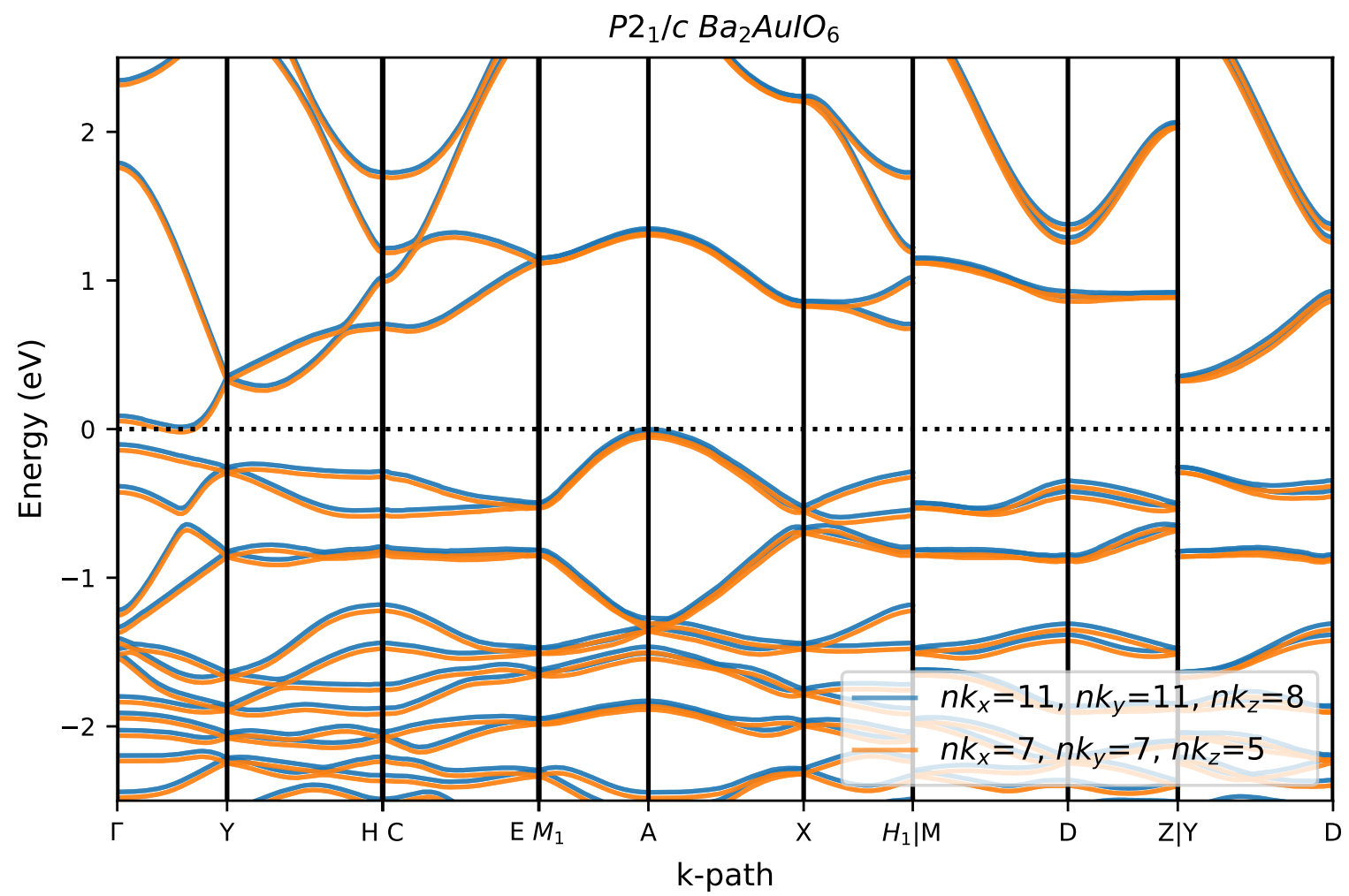

Figure S12: Increasing the number of k-points from $n k_{x}=7, n k_{y}=7, n k_{z}=5$ to $n k_{x}=11$, $n k_{x}=11, n k_{x}=8$ moves bands near the $E_{F} \sim 35 \mathrm{meV}$ higher in energy, placing $E_{F}$ firmly in the gap, in agreement with experiment. The gap between the bands immediately above and below the gap only changed from $0.184 \mathrm{eV}$ (fewer k-points) to $0.181 \mathrm{eV}$ (more k-points) indicating that this gap is converged. 


\section{References}

(1) Sleight, A. W.; Ward, R. Compounds of Post-Transition Elements with the Ordered Perovskite Structure. Inorganic Chemistry 1964, 3, 292-292.

(2) Kimmins, C. XXXIV - Contributions from the Laboratory of Gonville and Caius College, Cambridge. No. IX. Periodates. Journal of the Chemical Society, Transactions 1887, 51, 356-361.

(3) Stern, K. H. High Temperature Properties and Thermal Decomposition of Inorganic Salts with Oxyanions; CRC Press: Boca Raton, FL, 2000; p 251.

(4) Siebert, H.; Wieghardt, G. Vibrational spectra of Periodic Acid and Periodates, I: $\mathrm{H}_{5} \mathrm{IO}_{6}, \mathrm{H}_{6} \mathrm{IO}_{6}{ }^{+}$and $\mathrm{IO}_{6}{ }^{5-}$. Z. Naturforsch. 1972, 27, 1299-1304.

(5) Coblentz Society, In NIST Chemistry WebBook, NIST Standard Reference Database Number 69; Linstrom, P., Mallard, W., Eds.; National Institute of Standards and Technology: Gaithersburg, MD, 1969.

(6) Coblentz Society, In NIST Chemistry WebBook, NIST Standard Reference Database Number 69; Linstrom, P., Mallard, W., Eds.; National Institute of Standards and Technology: Gaithersburg, MD, 1969.

(7) Kubel, F.; Wandl, N.; Pantazi, M.; D’anna, V.; Hagemann, H. The Periodate-Based Double Perovskites $\mathrm{M}_{2} \mathrm{NaIO}_{6}(\mathrm{M}=\mathrm{Ca}$, Sr, and $\mathrm{Ba})$. Zeitschrift für anorganische und algemeine Chemie 2013, 892-898.

(8) Solyom, J. Fundamentals of the Physics of Solids, Volume 2-Electronic Properties, 1st ed.; Springer-Verlag Berlin Heidelberg: Budapest, Hungary, 2009; Chapter FreeElectron Model of Metals, pp 40-42.

(9) Gurevich, V.; Gavrichev, K.; Gorbunov, V.; Danilova, T.; Golushina, L.; Kho- 
dakovskii, I. Low-temperature heat capacity of witherite $\mathrm{BaCO}_{3}$. Geochemistry International 2001, 39, 1007-1014.

(10) Shulman, L. M. The heat capacity of water ice in interstellar or interplanetary conditions. Astronomy and Astrophysics 2004, 416, 187-190.

(11) Tari, A. The Specific Heat of Matter at Low Temperatures; Imperial College Press: London, UK, 2003; pp 6-7.

(12) Gopal, E. Specific Heat at Low Temperatures; Plenum Press: New York, New York, United States, 1966; pp 8-9. 